\title{
Identification of pearl millet [Pennisetum glaucum (L.) R. Br.] lines tolerant to soil salinity
}

\author{
L. Krishnamurthy $\cdot$ Rachid Serraj · Kedar Nath Rai • \\ C. Tom Hash · Abdullah J. Dakheel
}

Received: 7 March 2007 / Accepted: 17 April 2007/Published online: 18 May 2007

(C) Springer Science+Business Media B.V. 2007

\begin{abstract}
Crop tolerance to salinity is of high importance due to the extent and the constant increase in salt-affected areas in arid and semi-arid regions. Pearl millet (Pennistum glaucum), generally considered as fairly tolerant to salinity, could be an alternative crop option for salt affected areas. To explore the genotypic variability of vegetative-stage salinity tolerance, 100 pearl millet lines from ICRISAT breeding programs were first screened in a pot culture containing Alfisol with $250 \mathrm{mM} \mathrm{NaCl}$ solution as basal application. Subsequently, 31 lines including many parents of commercial hybrids, selected from the first trial were re-tested for confirmation of the initial salinity responses. Substantial variation for salinity tolerance was found on the basis of shoot biomass ratio (shoot biomass under salinity/non-saline control) and 22 lines with a wide range of tolerance varying from highly
\end{abstract}

L. Krishnamurthy $(\bowtie) \cdot R$. Serraj .

K. N. Rai · C. T. Hash

International Crops Research Institute for the Semi-Arid

Tropics (ICRISAT), Patancheru 502324 Andhra Pradesh, India

e-mail: L.Krishnamurthy@ cgiar.org

Present Address:

R. Serraj

CSWS-International Rice Research Institute (IRRI),

DAPO Box 7777, Metro Manila, Philippines

\section{A. J. Dakheel}

International Center for Biosaline Agriculture (ICBA), P.O. Box 14660, Dubai, United Arab Emirates tolerant to sensitive entries were identified. The performance of the genotypes was largely consistent across experiments. In a separate seed germination and seedling growth study, the seed germination was found to be adversely affected (more than $70 \%$ decrease) in more than half of the genotypes with $250 \mathrm{mM}$ concentration of $\mathrm{NaCl}$. The root growth ratio (root growth under salinity/control) as well as shoot growth ratio was measured at 6 DAS and this did not reflect the whole plant performance at 39 DAS. In general, the whole plant salinity tolerance was associated with reduced shoot $\mathrm{N}$ content, increased $\mathrm{K}^{+}$and $\mathrm{Na}^{+}$ contents. The $\mathrm{K}^{+} / \mathrm{Na}^{+}$and $\mathrm{Ca}^{++} / \mathrm{Na}^{+}$ratios were also positively related to the tolerance but not as closely as the $\mathrm{Na}^{+}$content. Therefore, it is concluded that a large scope exists for improving salt tolerance in pearl millet and that shoot $\mathrm{Na}^{+}$concentration could be considered as a potential non-destructive selection criterion for vegetative-stage screening. The usefulness of this criterion for salinity response with respect to grain and stover yield remains to be investigated.

Keywords Ionic distribution $\cdot \mathrm{K} / \mathrm{Na}$ ratio . Pennisetum glaucum . Salinity tolerance . Shoot biomass ratio $\cdot$ Shoot Na Content

\section{Introduction}

Salinity is a major constraint to crop production, especially in the arid and semi-arid areas of the 
world, where low precipitation, high surface evaporation, irrigation with saline water, rising water tables and poor irrigation practices generally increase the level of soluble salts (Ashraf 1994; Hollington 1998; Houshmand et al. 2005). As an example, soil salinity levels measured as an EC of 3.3-3.8 $\mathrm{dS} \mathrm{m}^{-1}$ were shown to reduce durum wheat yields by $58-81 \%$ (Houshmand et al. 2005). Salinity management options through soil reclamation and/or improved irrigation techniques in the arid and semi-arid tropics are viable but often prohibitively expensive in poor developing countries. On the other hand, crop improvement could be a less expensive and more sustainable solution for agricultural use of saltaffected areas. Most of the pearl millet is grown as grain and fodder crop in the arid and semi-arid zones of south Asia and west Africa (Blummel et al. 2003), where the soils are often prone to salinity problems which affect the crop productivity. Pearl millet is also a potential crop to grow in the rice fallows of saline areas in south Asia, where typical increases of salinity levels during post-rainy season prevent crop production. Therefore, improved tolerance could help intensify the production under this environment (Bidinger and Hash 2003). Crops species vary in their sensitivity to salinity (Francois and Maas 1994; Serraj et al. 1998; Munns et al. 2002). Pearl millet [Pennisetum glaucum (L.) R. Br.] and its wild relatives are rated to be fairly tolerant to salinity (Mass and Hoffman 1977; Shannon 1984; Ashraf and McNeilly 1987; http://www.biosalinity.org/salt-tolerant_plants.htm) and provide an option while selecting crops that can be more profitably grown in saline soils (Chopra and Chopra 1993).

Lack of a single reproducible screening protocol and lack of knowledge on trait(s) that confer yield under salinity is a great limitation to breeding tolerant varieties. Field screening under salinity stress may not be effective because of the extent of variability in salinity experienced within a single field and among plots even at shorter distances (Richards and Dennet 1980). Pearl millet seems to be sensitive at germination stage in ECe of $16 \mathrm{dS} \mathrm{m}^{-1}$ and beyond but this sensitivity is to some extent compensated by the tillering capability (Dua 1989). However, it seems that salinity response estimated at germination stage does not correlate well with plant performance at later stages (Munns and James 2003). $\mathrm{Na}^{+}$exclusion and grain $\mathrm{K} / \mathrm{Na}$ ratios were suggested to be reliable traits for selection. However, their usefulness as selection criteria (Munns and James 2003; Poustini and Siosemardeh 2004) was not demonstrated with five cultivars in pearl millet (Ashraf and McNeilly 1987) and therefore this relationship needs to be evaluated with a wider range of genotypes. Overall, it seems that although various aspects have been related to tolerance, the variation in whole plant reaction to salinity has been suggested to provide the best means of initial isolation of salinity tolerant genotypes (Shannon 1984; Ashraf and McNeilly 1987).

Large genotypic variation was reported to exist in pearl millet for salinity response in terms of whole plant response (Ashraf and McNeilly 1987, 1992; Dua 1989). Moreover, availability of high levels of tolerance in other species of Pennisetum (Ashraf and McNeilly 1987, 1992; Muscolo et al. 2003) and within the P. glaucum (Dua 1989) offers a scope for understanding the traits related to tolerance and to integrate these tolerant crop species/genotypes into appropriate management programs to improve the productivity of the saline soils.

Quantitative trait loci (QTLs) for salt tolerance have been mapped in several cereals including rice (Flowers et al. 2000; Koyama et al. 2001; Takehisa et al. 2004; Ren et al. 2005), barley (Ellis et al. 1997; Mano and Takeda 1997) and bread wheat (Quarrie et al. 2005; Ma et al. 2007) with markers not adequately robust enough to use across a range of germplasm and a range of salinity conditions. The limited success of these studies was suggested to be likely due to limited amount of diversity available within the modern cultivars which were used as parents (Munns et al. 2002). Therefore, it seems necessary to identify traits that are highly related to salinity tolerance through a simple and repeatable screening method and to select genotypes with high levels of polymorphism for use in molecular studies.

The objectives of the present study were to identify the extent of genotypic variation for salinity tolerance measured as a proportion of shoot biomass production under saline condition as that of nonsaline control during the early vegetative stage among the range of currently used breeding lines at ICRISAT, to identify physiological traits that could be used as potential screening criteria and to evaluate the potential use of seed germination and seedling growth responses for predicting the whole plant responses of genotypes to salinity. 


\section{Materials and methods}

Pot culture screening

In the first pot experiment, 100 entries comprising 35 hybrid parental lines, 61 population progenies, 2 popular open-pollinated varieties and 2 germplasm accessions were exposed to $\mathrm{NaCl}$ salinity using a randomized complete block design with three replications. Pots of $12.5-\mathrm{cm}$ diameter were filled with $1.2 \mathrm{~kg}$ of Alfisol mixed with di-ammonium phosphate at the equivalent rate of $200 \mathrm{~kg} \mathrm{ha}^{-1}$ on 29 Mar 2003 , and sealed at the bottom to avoid salt loss. Two levels of salinity were applied prior to sowing through a one-time application of deionized water with and without $250 \mathrm{mM} \mathrm{NaCl}$. The amount of water added to bring the soil to field capacity was determined on a soil weight basis $(23.2 \% \mathrm{w} / \mathrm{w})$. The resulting solution EC was $23.4 \mathrm{dS} \mathrm{m}^{-1}$ and the $\mathrm{NaCl}$-treated soil ECe was $18.1 \pm 0.19 \mathrm{dS} \mathrm{m}^{-1}$, compared to $2.9 \pm 0.26$ without $\mathrm{NaCl}$. Irrigation was provided on alternate days up to 20 days after sowing (DAS) and every day at later stages of growth to replace evapotranspirational losses and bring soil moisture levels to field capacity. The water needed for these subsequent irrigations was determined by daily weighing of 10 representative pots, to avoid either water logging or water deficit in the pots. Sixteen seeds of each genotype were sown in each pot in four equally spaced hills. A maximum of four plants pot $^{-1}$ were retained after thinning at 10 DAS. One plant per pot was sampled at 18, 25, 32 and 39 DAS. In case a pot had less than four plants, the plants were reserved for the later sampling stage(s), and earlier sampling was skipped. The harvested plants were separated into root (extractable) and shoot, dried in hot air draught oven at $60^{\circ} \mathrm{C}$ for 3 days and the dry weights were recorded. A ratio of shoot biomass measured under salinity to that of control, used as a proxy for estimating the salinity tolerance for biomass production at vegetative stage, was calculated replicate-wise for each sampling time.

A second pot experiment (Experiment 2) was conducted only with 31 hybrid parental lines tested in the first experiment and was sown on 17 Sep 2003. The experimental procedure was the same as in experiment 1 , except that the pot size was $15-\mathrm{cm}$ diameter, contained 2-kg Alfisol, and all plants were harvested at the same time at 35 DAS.
Soil and plant assessment

Ionic contents of shoots were estimated using the sample harvested at 39 days after sowing from experiment 1 . The pooled shoots (stem + leaves) of all the three replications were used for the determination of $\mathrm{N}, \mathrm{P}, \mathrm{K}, \mathrm{Na}$ and $\mathrm{Ca}$. One hundred and fifty milligrams of finely ground shoot sample was digested in $4 \mathrm{ml}$ of concentrated sulfuric acid with $0.5 \%$ selenium powder at $360^{\circ} \mathrm{C}$ for $75 \mathrm{~min}$ on a block digester and the digest was diluted to $75 \mathrm{ml}$. Using this digest, total $\mathrm{N}$ was estimated using SKALAR Auto Analyzer, Netherlands (Krom 1980) to determine whether $\mathrm{N}$ absorption has any role in reducing plant growth under saline conditions. Exchangeable K, Na and Ca were estimated (Sahrawat et al. 2002) using an atomic absorption spectrophotometer (Varion model 1200, Australia).

The EC (electrical conductivity) of the $\mathrm{NaCl}$ solutions was measured directly using a conductivity meter (Model 1481-50, Cole-Parmer Instrument Company, Chicago). The soil EC was measured using a 1:2 (soil: water; w/v) extract.

\section{Germination studies}

Twenty seeds of each of the 100 entries were surface sterilized with $1 \%$ sodium hypochlorite solution for $10 \mathrm{~min}$, and germinated on filter paper in closed petri dishes for 6 days in $15 \mathrm{ml}$ deionized water (control) or in $15 \mathrm{ml}$ of a $250 \mathrm{mM} \mathrm{NaCl}$ solution in a randomized complete block design with three replications in a growth chamber at $28 / 25^{\circ} \mathrm{C}$ day/night temperature with 12-h light. Five representative seedlings from each petri dish were used for the measurement of root and shoot length. Relative seed germination (RSG) was calculated as the ratio of the number of seeds germinated under saline conditions to the number of those germinated in control, relative root length (RRL) as the ratio of root length under saline conditions to the mean root length of control, and relative shoot length (RSL) as the ratio of shoot length under saline conditions to the mean shoot length of control. These variables were subjected to statistical analysis as outlined in the next section. The resulting best linear unbiased predictors (BLUPs) for each trait were used to estimate correlations and regressions among RSG, RRL, RSL, and shoot 
biomass ratio observed under different stages of vegetative growth.

\section{Statistical analysis}

The data on each variate from individual experiments were analyzed using the following linear additive mixed effects model

$Y_{i k}=\mu+r+g_{k}+e_{i k}$

where $Y_{i k}$ is the observation on genotype $k$ in block $i$, $\mu$ is the general mean, $r_{i}$ is the effect of block $i, g_{k}$ is the effect of genotype $k$, and $e_{i k}$ is the plot error. The general mean $\mu$ and block effect $r_{i}$ were considered as fixed. The genotype effect $g_{k}$, and the error term $e_{i k}$, were assumed as random effects, each with mean zero and constant variances $\sigma_{g}^{2}$ and $\sigma_{e}^{2}$ respectively. Using the above model, residual maximum likelihood (ReML) was used to obtain the unbiased estimates of the variance components $\sigma_{g}^{2}$ and $\sigma_{e}^{2}$, and the BLUPs of the performance of the 100 genotypes in the first and 31 genotypes in the second experiment. Heritability was estimated as $h^{2}=\sigma_{g}^{2} /\left(\sigma_{g}^{2}+\sigma_{e}^{2}\right)$. The significance of genetic variability among genotypes was assessed from the standard error of the estimate of genetic variance $\sigma_{g}^{2}$, assuming the ratio $\sigma_{g}^{2} / \operatorname{SE}\left(\sigma_{g}^{2}\right)$ to follow normal distribution asymptotically.

Geometric mean ( $n^{\text {th }}$ root of the product of $n$ observations) of shoot biomass ratios was calculated from the four BLUPs of the four DAS for each genotype for the first experiment. These geometric means of the first experiment and the BLUPs of second experiment for 31 common genotypes were

Table 1 Trial means, range of predicted means, genetic variance and heritability for shoot biomass ratio (shoot biomass under salinity/shoot biomass under control) for pearl millet

\begin{tabular}{lllll}
\hline Sampling time & \multicolumn{2}{l}{ Ratio of shoot biomass } & & \\
\cline { 2 - 5 } & Trial mean & Range of predicted means & $\sigma_{g}^{2}(\mathrm{SE})$ & Heritability $\left(h^{2}\right)$ \\
\hline Experiment $1(n=100)$ & & & & $0.0027(0.0007)$ \\
18 DAS & 0.048 & $0.020-0.198$ & 0.33 \\
25 DAS & 0.080 & $0.023-0.344$ & $0.0083(0.0017)$ & 0.45 \\
32 DAS & 0.127 & $0.047-0.390$ & $0.0112(0.0028)$ & 0.36 \\
39 DAS & 0.313 & $0.107-0.633$ & $0.0292(0.0065)$ & 0.39 \\
Experiment 2 $(n=31)$ & & & & $0.0013(0.0005)$ \\
35 DAS & 0.049 & $0.014-0.133$ & & $0.45 \mathrm{~m}$ \\
\hline
\end{tabular}

used for grouping them into a few distinct groups by a hierarchical cluster analysis using Ward's incremental sum of squares method. All the statistical analyses were carried out using GenStat, Release 6.1 (Payne 2002).

\section{Results}

Pot culture screening

In the current study the genotypic variability for salinity tolerance was assessed, based on the ratio of shoot (stem + leaf) biomass produced under salinity as that of control. Large genotypic variation was found for the shoot biomass ratio at all stages of crop growth both in experiment 1 and 2 (Table 1). The heritability values observed for the four samples of experiment 1 and the single one-time sample of experiment 2 ranged from 0.33 to 0.45 .

The hierarchical cluster analysis had yielded five distinct groups at a similarity index of 0.90 and the entries in groups with top one (highly tolerant) and two (moderately tolerant) and the bottom (highly sensitive) shoot biomass ratios were identified (Table 2).

Ion distribution

Shoot $\mathrm{Na}^{+}$content under saline condition was negatively correlated with shoot biomass ratio (Fig. 1A; $\left.r^{2}=0.39 ; P=<0.001\right)$. This relationship improved further with the mean shoot biomass under salinity (Fig. 1B; $r^{2}=0.43 ; P=<0.001$ ). Shoot $\mathrm{Na}^{+}$content

genotypes at 18, 25, 32 and 39 DAS in experiment 1 and shoot biomass ratio at 35 DAS in experiment 2 
Table 2 The shoot biomass ratio of pearl millet genotypes that clustered into highly tolerant, tolerant and sensitive groups based on hierarchical cluster analysis (Ward's ISS method) using the data of experiment 1 (geometric mean of 18, 25, 32 and 39 day ratios) and the 35 day ratio of experiment 2

\begin{tabular}{|c|c|c|}
\hline \multirow[t]{2}{*}{ Genotypes } & \multicolumn{2}{|c|}{ Mean shoot biomass ratio } \\
\hline & $\begin{array}{l}\text { Experiment } \\
1\end{array}$ & $\begin{array}{l}\text { Experiment } \\
2\end{array}$ \\
\hline \multicolumn{3}{|l|}{ Highly tolerant } \\
\hline HTP 94/54 (HHB 146 pollinator) & 0.234 & 0.083 \\
\hline CZI 9621 & 0.206 & 0.074 \\
\hline $\begin{array}{l}\text { ICMP } 451 \text { (ICMH } 451 \\
\text { pollinator) }\end{array}$ & 0.151 & 0.118 \\
\hline IP 3757 & 0.128 & 0.133 \\
\hline \multicolumn{3}{|l|}{ Moderately tolerant } \\
\hline $863-\mathrm{B}$ & 0.097 & 0.068 \\
\hline ICMB 02111 & 0.104 & 0.073 \\
\hline ICMB 94555 & 0.079 & 0.062 \\
\hline ICMB 95333 & 0.080 & 0.061 \\
\hline ICMB 00888 & 0.112 & 0.041 \\
\hline PRLT 2/89-33 & 0.130 & 0.051 \\
\hline ICMB 01222 & 0.135 & 0.068 \\
\hline CZI 98-11 & 0.170 & 0.069 \\
\hline IP 3732 & 0.149 & 0.095 \\
\hline \multicolumn{3}{|l|}{ Highly sensitive } \\
\hline ICMB 95111 & 0.069 & 0.037 \\
\hline ICMB 95222 & 0.059 & 0.030 \\
\hline ICMB 96333 & 0.067 & 0.030 \\
\hline ICML 22 & 0.074 & 0.035 \\
\hline Tift 23D2B1-P5 & 0.051 & 0.047 \\
\hline H 77/833-2 (HHB 67 pollinator) & 0.060 & 0.014 \\
\hline 81-B & 0.039 & 0.014 \\
\hline MIR 220 & 0.046 & 0.014 \\
\hline J 104 Selection & 0.077 & 0.016 \\
\hline
\end{tabular}

under control did not show any such relationship with the actual shoot biomass under control (data not shown). The overall average shoot $\mathrm{Na}^{+}$content under salinity $(0.99 \%)$ was about four times higher than that under control conditions $(0.24 \%)$ and ranged from 0.35 to $2.66 \%$

Shoot $\mathrm{K}^{+}$content under saline conditions was also positively related to the shoot biomass ratio $\left(r^{2}=0.18, P=<0.001\right)$. The strength of this relationship improved further with the shoot biomass under salinity $\left(r^{2}=0.24, P=<0.001\right)$. Unlike the $\mathrm{Na}^{+}$ content, the mean change in overall mean $\mathrm{K}^{+}$content
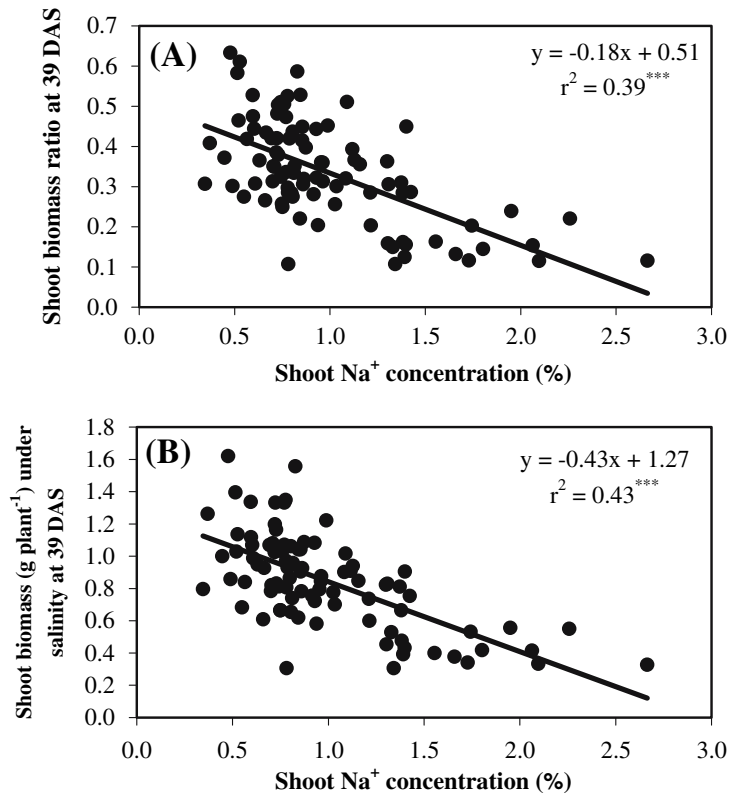

Fig. 1 Relationship of shoot $\mathrm{Na}^{+}$concentration (\%) with (A) shoot biomass ratio at 39 DAS and (B) with shoot biomass under salinity $\left(\mathrm{g} \mathrm{plant}^{-1}\right)$ at 39 DAS in pearl millet entries. (*** denotes significance at a probability level of 0.001 )

under salinity $(1.27 \%)$ was not that different from that of the one under control $(1.55 \%)$. The $\mathrm{K}^{+} / \mathrm{Na}^{+}$ ratio was positively associated with the shoot biomass ratio at 39 DAS $\left(r^{2}=0.21, P=<0.001\right.$; Fig. 2 A). Also this relationship was much higher with the shoot biomass under salinity $\left(r^{2}=0.28, P=<0.001\right)$. The overall mean of $\mathrm{K}^{+} / \mathrm{Na}^{+}$ratio was about 1.7 under saline conditions, substantially lower than that under the non-saline control (about 6.6).

$\mathrm{Ca}^{++}$content was not correlated either to the shoot biomass ratio or to the shoot biomass under salinity. By contrast, the $\mathrm{Ca}^{++} / \mathrm{Na}^{+}$ratio was positively correlated to both shoot biomass ratio $\left(r^{2}=0.17, P\right.$ $<0.001$; Fig. 2B) as well as the shoot biomass under salinity $\left(r^{2}=0.23, P<0.001\right)$.

Under saline condition, the $\mathrm{N}$ concentration of shoots was negatively correlated with shoot biomass ratio $\left(r^{2}=0.32, P=<0.001\right.$; Fig. 3$)$ as well as the shoot biomass under salinity $\left(r^{2}=0.35, P=<0.001\right)$, whereas under control conditions this correlation was not significant. This result also indicated that the salinity-tolerant entries had relatively lower $\mathrm{N}$ concentration, varying from 0.3 to about $1.3 \%$ (Fig. 3). This was likely due to the fact that tolerant plants maintained relatively higher growth rates and thus 

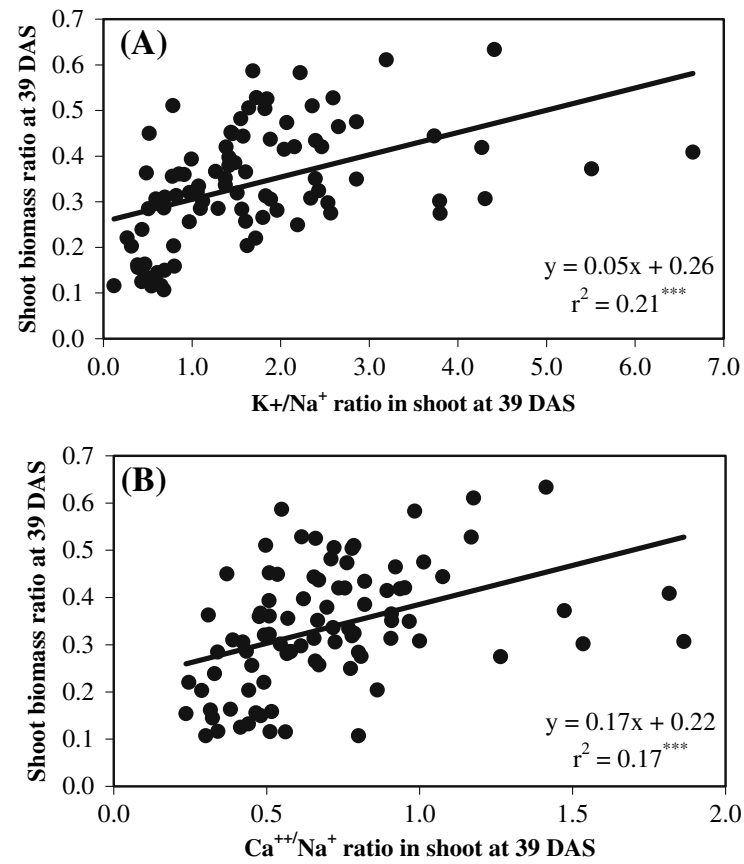

Fig. 2 Relationship of (A) shoot $\mathrm{K}^{+} / \mathrm{Na}^{+}$ratio and (B) shoot $\mathrm{Ca}^{++} / \mathrm{Na}^{+}$ratio with the total dry matter plant ${ }^{-1}$ of pearl millet entries under salinity at 39 days after sowing. (*** denotes significance at a probability level of 0.001 )

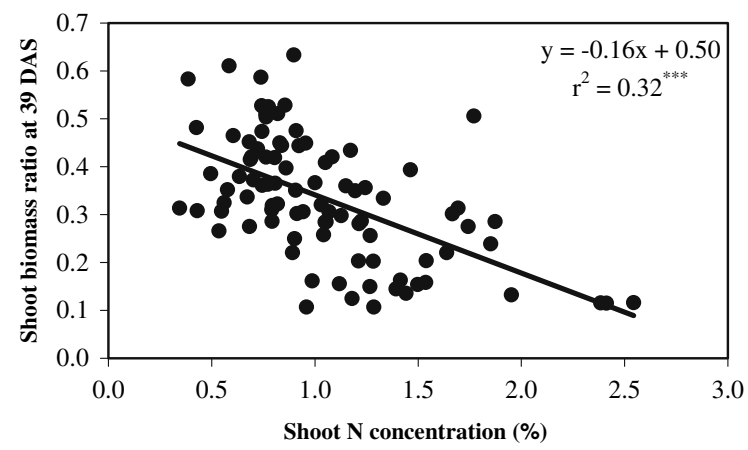

Fig. 3 Relationship of shoot $\mathrm{N}$ concentration (\%) with the shoot biomass ratio at 39 DAS of pearl millet entries. (*** denotes significance at a probability level of 0.001 )

Table 3 Trial means, range of predicted means, genetic variance and heritability for the ratio of seeds germinated in $250 \mathrm{mM}$ saline solution as that of control (\%) (RSG), ratio of root length under salinity as that of control (RRL) and the ratio "diluting" the amount of $\mathrm{N}$ taken up, while reduced growth in sensitive entries resulted in higher $\mathrm{N}$ concentrations in the shoot. In general, $\mathrm{N}$ acquisition by plants seems to have been affected under salinity, as indicated by the overall environmental means. The overall mean $\mathrm{N}$ concentration under saline conditions was $1.05 \%$, compared to $1.42 \%$ in the non-saline control.

\section{Germination studies}

Twenty one entries that showed $<80 \%$ germination under control conditions were excluded from the study of the variation in seed germination under salinity and in subsequent evaluation of its relationship with root and shoot growth under salinity at seedling stage with the shoot biomass ratios at different stages of growth, to avoid confusion between poor seed germination and salt effects on early vegetative growth. There was significant genotypic variation in the response of germination to salinity as measured by the ratio of germination under salinity to that of control (RSG) (Table 3). There was a large range of variation for the RSG among the entries tested (Table 3). RSG was 0.1 to 0.4 in 11 progenies and in one genotype RIB 3135-18 (Pollinator of hybrid RHB 12) indicating that these entries are highly sensitive to seed germination under salinity. It was between 0.4 and 0.7 in 12 progenies and in some of the B-lines such as ICMB 94111, ICMB 89111, ICMB 96444, 843B, ICMB 95222, ICMB 98111, ICMB 00888 and 863B indicating that these were moderately sensitive. Thirty-three entries, including 15 progenies and 18 parental lines had more than 0.8 RSG. It is notable that all the highly tolerant entries based on the shoot biomass ratio listed in Table 2 possessed an RSG of $>0.8$.

Besides seed germination, the ratio of root and shoot growth of the seedlings, estimated as length

of shoot length under salinity as that of control (RSL) in the 79 pearl millet entries that showed $>80 \%$ germination under control

\begin{tabular}{llccc}
\hline Trait & Trial mean & Range of predicted means & $\sigma_{g}^{2}(\mathrm{SE})$ & Heritability $\left(h^{2}\right)$ \\
\hline RSG & 0.684 & $0.11-1.07$ & $0.0602(0.0106)$ & 0.77 \\
RRL & 0.198 & $0.054-0.461$ & $0.0100(0.0017)$ & 0.80 \\
RSL & 0.273 & $0.045-0.480$ & $0.0092(0.0017)$ & 0.70 \\
\hline
\end{tabular}


under salinity to that of control, also varied greatly across entries (Table 3). Root growth was relatively more affected by salinity than shoot growth as shown by the overall means and the ranges of these two traits (Table 3). The significance pattern of the genetic correlations, while relating RSG, RRL and RSL of the seedlings with the shoot biomass ratio at $18,25,32$ and 39 DAS, was largely the same as that of the phenotypic correlation (Table 4). RSG exhibited high levels of positive correlation, both genetic as well as phenotypic, with the shoot biomass ratios recorded at all the stages of growth. Genetic correlation showed that RRL was related to shoot biomass ratio at 39 DAS and the phenotypic correlation showed both RRL and RSL was correlated with the shoot biomass ratio at 39 DAS (Table 4). The correlation coefficients obtained with shoot biomass under salinity instead of shoot biomass ratio were also largely of similar values (data not shown).

\section{Discussion}

The main purpose of this study was to assess the range of variation for salinity tolerance with respect to biomass yield, an important consideration in breeding forage cultivars. Entries with contrasting relative shoot biomass ratio (shoot biomass yield under salinity/shoot biomass yield under non-saline control), a measure of salinity tolerance, were identified. The most tolerant entries included some of the restorers such as HTP 94/54 (pollinator of a released hybrid HHP 146) and ICMP 451, an openpollinated variety CZI 9621 and a germplasm accession, IP 3757. The moderately tolerant entries included some of the B-lines, which are also parental lines of released hybrids such as $863 \mathrm{~B}$ and ICMB 94555. Similarly, the highly sensitive entries also included B-lines (81B, ICMB 95111, ICMB 96333) and restorer lines (H 77/833-2 and MIR 220). The poor value of using salinity tolerance at seedling stage was also confirmed. Further shoot $\mathrm{Na}^{+}$concentration emerged as an indirect non-destructive selection criterion.

Measuring the biomass production at 39 days after sowing following saturation of the soil to field capacity with a $250 \mathrm{mM} \mathrm{NaCl}$ solution has provided a reasonably good screening method to identify tolerant sources in relative biomass production in the early vegetative stages under saline conditions, and has revealed substantial variation among entries. The salt concentration $(250 \mathrm{mM} \mathrm{NaCl}$ resulting in a soil ECe of $18.1 \pm 0.19 \mathrm{dS} \mathrm{m}^{-1}$ ) chosen for screening, was similar to that in some previous studies on

Table 4 Genetic and phenotypic correlations of the shoot biomass ratios (salinity/control) (SBR) observed at 18, 25, 32 and 39 days after sowing with the relative seed germination

\begin{tabular}{|c|c|c|c|c|c|c|}
\hline Traits & $\begin{array}{l}\text { SBR } \\
(18 \mathrm{DAS})\end{array}$ & $\begin{array}{l}\text { SBR } \\
\text { (25 DAS) }\end{array}$ & $\begin{array}{l}\text { SBR } \\
\text { (32 DAS) }\end{array}$ & $\begin{array}{l}\text { SBR } \\
39 \text { DAS }\end{array}$ & RSG & RRL \\
\hline \multicolumn{7}{|c|}{ Genetic correlation } \\
\hline SBR (25DAS) & $0.675 * * *$ & & & & & \\
\hline SBR (32DAS) & $0.648 * * *$ & $0.791 * * *$ & & & & \\
\hline SBR (39DAS) & $0.464 *$ & $0.516 * *$ & $0.519 * *$ & & & \\
\hline RSG & $0.560 * * *$ & $0.386^{* *}$ & $0.527 * * *$ & $0.469 * *$ & & \\
\hline RRL & 0.067 & 0.237 & 0.089 & $0.335^{*}$ & $0.398 * * *$ & \\
\hline RSL & 0.247 & 0.036 & 0.113 & 0.211 & $0.415 * * *$ & $0.649 * * *$ \\
\hline \multicolumn{7}{|c|}{ Phenotypic correlation } \\
\hline SBR (25DAS) & $0.366^{* * *}$ & & & & & \\
\hline SBR (32DAS) & $0.323 * * *$ & $0.488 * * *$ & & & & \\
\hline SBR (39DAS) & $0.191 * *$ & $0.336 * * *$ & $0.411 * * *$ & & & \\
\hline RSG & $0.218 * *$ & $0.242 * *$ & $0.292^{* * *}$ & $0.267 * * *$ & & \\
\hline RRL & 0.038 & 0.114 & 0.059 & $0.173^{*}$ & $0.374 * * *$ & \\
\hline RSL & 0.108 & 0.030 & 0.077 & $0.153^{*}$ & $0.374 * * *$ & $0.613 * * *$ \\
\hline
\end{tabular}

$*$, ** and $* * *$ denotes significance at probability levels $0.05,0.01$ and 0.001 , respectively 
screening of pearl millet (e.g. Dua 1989; Ashraf and McNeilly 1987, 1992; Muscolo et al. 2003). However, few others have also used lower concentrations in their study (Dua 1989; Albassam 2001). In the present study, this level of salinity was used to cover the salinity-affected soil levels that occur in most pearl millet growing areas globally as a large number of previous workers have chosen $15-20 \mathrm{dS} \mathrm{m}^{-1}$ as medium concentration for screening large number of pearl millet entries. The level of salt concentration used in the present study seemed suitable for screening this crop species as only few entries could reach a ratio of 0.50 at 39 DAS in this study under salinity as that of control.

The shoot $\mathrm{Na}^{+}$concentration under saline conditions appeared to be most closely related to the shoot biomass ratio $\left(r^{2}=0.39, P \geq 0.001\right)$ or shoot biomass production under salinity $\left(r^{2}=0.43, P \geq 0.001\right)$. The use of shoot $\mathrm{Na}^{+}$concentration to predict the shoot biomass ratio would certainly deserve more investigation for consideration as a trait for screening plants grown under saline conditions. If compared with sorghum, that has been found to be an efficient excluder of $\mathrm{Na}^{+}$, restricting its accumulation in the roots (Weinberg et al. 1984; Grieve and Mass 1988) and stem but excluding most of it from the top leaves (Netondo et al. 2004) pearl millet does not seem to be as efficient excluder of $\mathrm{Na}^{+}$from the shoot. The mean $\mathrm{Na}^{+}$concentration in the shoots of all the 100 entries of pearl millet in the present study was $1.0 \%$, four times higher than that observed under control $(0.24 \%)$ and twice higher than that observed in sorghum under the same saline environment (Krishnamurthy et al. 2007). However, there was a large range of variation available $(0.35$ to $2.66 \%)$ for $\mathrm{Na}^{+}$ concentration among pearl millet entries for possible exploitation as a selection criterion. Occurrence of similar range of variation in $\mathrm{Na}^{+}$concentration in wheat had lead to suggestion of using this trait for use in screening (Omielan et al. 1991; Poustini and Siosemardeh 2004; Munns and James 2003). This trait would also have the advantage of being non-destructive. The $\mathrm{K}^{+} / \mathrm{Na}^{+}$and $\mathrm{Ca}^{++} / \mathrm{Na}^{+}$ratios were also well correlated with biomass production under salinity $\left(r^{2}\right.$ close to 0.2 ) but the relationship was not that strong to serve as a screen. The relative seed germination under salinity as that of control was largely well correlated with the shoot biomass ratios at all vegetative stages. In addition, all the top tolerant entries for shoot biomass had the highest relative seed germination. However in sorghum, relative seed germination has been found not to be related to the shoot biomass ratios at later vegetative stages (Krishnamurthy et al. 2007) indicating that the seed germination in itself was affected at a solution EC of $23 \mathrm{dS} \mathrm{m} \mathrm{m}^{-1}$ in some entries of pearl millet. This germination differences can be of use for discarding large number of genotypes in the preliminary screening and thereby improve the efficiency of the advanced screening. However, root and shoot growth observations at seedling stage are likely to be less important in pearl millet though seedling relative shoot growth vigor had been found to be both genetically and phenotypically correlated to some extent to the shoot biomass ratios $1 \mathrm{t} 18,25,32$ and 39 DAS in sorghum (Krishnamurthy et al. 2007).

Heritability values for shoot biomass ratios ranged from 0.33 to 0.45 showing that selection for this trait would be fairly effective. There may be a scope to further improve the screening efficiency for shoot biomass ratio and its operational heritability values by sampling larger numbers of plants at one time. In relatively more sensitive crop like rice, for the trait $\mathrm{K}^{+} / \mathrm{Na}^{+}$ratio measured at $12 \mathrm{dS} \mathrm{m}{ }^{-1}$ culture medium, the heritability values reported were low (narrow sense $=0.198$ and broad sense $=0.367)($ Gregorio and Senadhira 1993).

Overall, it can be concluded that substantial variation in early vegetative stage salinity tolerance among pearl millet entries was found in this study and several relatively salinity tolerant and sensitive pearl millet entries for shoot biomass production were identified. The $\mathrm{Na}^{+}$concentration in the shoot was proposed as a potential proxy for phenotyping pearl millet genotypes for salinity tolerance as this trait was found to be well related to the ratio of shoot biomass. However, further investigation would be needed before using this trait as a screening measure. Seed germination under salinity as that of control has proved to be a potential trait for discarding sensitive entries initially. Early root or shoot growth of seedlings in response to salinity may not be useful as traits for selection as they were not related to biomass productivity at anthesis. Further work is under progress to elucidate the physiological and genetic mechanisms of salinity response and to implement a marker-assisted selection program for salinity tolerance in pearl millet. 
Acknowledgments This research was initially supported by core funds of ICRISAT and later by OPEC Fund for International Development assigned to biotechnology-assisted improvement in salinity tolerance through the GTBiotechnology of ICRISAT. The authors gratefully acknowledge the guidance on statistical analysis provided by Dr S Chandra, Principal Scientist (Biometrics), ICRISAT.

\section{References}

Albassam BA (2001) Effect of nitrate nutrition on growth and nitrogen assimilation of pearl millet exposed to sodium chloride stress. J Plant Nutr 24:1325-1335

Ashraf M (1994) Breeding for salinity tolerance in plant. Crit Rev Plant Sci 13:17-42

Ashraf M, McNeilly T (1987) Salinity effects on five cultivars/ lines of pearl millet (Pennisetum americanum [L.] Leeke). Plant Soil 103:13-19

Ashraf M, McNeilly TM (1992) The potential for exploiting variation in salinity tolerance in pearl millet (Pennisetum americanum [L.] Leeke). Plant Breed 104:234- 240

Bidinger FR, Hash CT (2003) Pearl millet. In: Nguyen HT, Blum A (eds) Physiology and biotechnology integration in plant breeding. Marcel Dekker, New York, pp 225-270

Blummel M, Zerbini E, Reddy BVS, Hash CT, Bidinger F, Khan AA (2003) Improving the production and utilization of sorghum and pearl millet as livestock feed: progress towards dual-purpose genotypes. Field Crops Res 84:143158

Chopra N, Chopra N (1993) Relative salt tolerance of pearl millet (Pennisetum glaucum) varieties in Marwar tract of Rajasthan. Ind J Agric Res 63:652-654

Dua RP (1989) Salinity tolerance in pearl millet. Indian J Agric Res 23:9-14

Ellis RP, Forster BP, Waugh R, Bonar N, Handley LL, Robinson D, Gordon DC, Powell W (1997) Mapping physiological traits in barley. New Phytol 137:149-157

Flowers TJ, Koyama ML, Flowers SA, Sudhakar C, Singh KP, Yeo AR (2000) QTL: their place in engineering tolerance of rice to salinity. J Exp Bot 51:99-106

Francois LE, Mass EV (1994) Crop response and management on salt-affected soils. In: Pessarakli M (ed) Handbook of plant and crop stress. Marcel Dekker, New York, USA, pp 149-181

Gregorio GB, Senadhira D (1993) Genetic analysis of salinity tolerance in rice (Oryza sativa L.). Theor Appl Genet 86:333-338

Grieve CM, Mass EV (1988) Betaine accumulation in saltstressed sorghum. Physiol Plant 61:167-171

Hollington PA (1998) Technological breakthroughs in screening and breeding wheat varieties for salt tolerance. In: Gupta SK, Sharma SK, Tyagi NK (eds) Proceedings of the national conference on salinity management in agriculture. CSSRI, Karnal, India, pp 273-289

Houshmand S, Arzani A, Maibody SAM, Feizi M (2005) Evaluation of salt-tolerant genotypes of durum wheat derived from in vitro and field experiments. Field Crops Res 91:345-354
Koyama ML, Levesley A, Koebner RMD, Flowers TJ, Yeo AR (2001) Quantitative trait loci for component physiological traits determining salt tolerance in rice. Plant Physiol 125:406-422

Krishnamurthy L, Serraj R, Hash CT, Dakheel AJ, Reddy BVS (2007) Screening sorghum genotypes for salinity tolerance biomass production. Euphytica http://www.springerlink.com/content/u61106863t6123p1/fulltext.html

Krom M (1980) Spectrometric determination of ammonia; a study of modified Berthlot reaction using salicilate and dichloroisocyanurate. The Analyst 105:305-316

Ma L, Zhou E, Huo N, Zhou R, Wang G, Jia Z (2007) Genetic analysis of salt tolerance in a recombinant inbred population of wheat (Triticum aestivum L.). Euphytica 153:109-117

Mano Y, Takeda K (1997) Mapping quantitative trait loci for salt tolerance at germination and the seedling stage in barley (Hordeum vulgare L.). Euphytica 94:263-272

Mass EV, Hoffman GJ (1977) Crop salt tolerance-current assessment. J Drainage Div Am Soc Civ Engrs 103:115134

Munns R, Husain S, Rivelli AR, James RA, Condon AG, Lindsay MP, Lagudah ES, Schachtman DP, Hare RA (2002) Avenues for increasing salt tolerance of crops, and the role of physiologically based selection traits. Plant Soil 247:93-105

Munns R, James RA (2003) Screening methods for salinity tolerance: a case study with tetraploid wheat. Plant Soil 253:201-218

Muscolo A, Panuccio MR, Sidari M (2003) Effects of salinity on growth, carbohydrate metabolism and nutritive properties of kikuyu grass (Pennisetum clandestinum Hochst). Plant Sci 104:1103-1110

Netondo GW, Onyango JC, Beck E (2004) Sorghum and salinity I. Response of growth, water relations, and ion accumulation to $\mathrm{NaCl}$ salinity. Crop Sci 44:707-710

Omielan JA, Epstein E, Dvorak J (1991) Salt tolerance and ionic relations of wheat as affected by individual chromosomes of salt-tolerant Lophopyrum elongatum. Genome 34:961-974

Payne RW (ed) (2002) The guide to GenStat (R) Release 6.1. Part 2: Statistics. VSN International Ltd, Oxford, UK

Poustini K, Siosemardeh A (2004) Ion distribution in wheat cultivars in response to salinity stress. Field Crops Res 85:125-133

Quarrie SA, Steed A, Calestani C, Semikhodskii A, Lebreton C, Chinoy C, Steele N, Pljevljakusic D, Waterman E, Weyen J, Schondelmaier J, Habash DZ, Farmer P, Saker L, Clarkson DT, Abugalieva A, Yessimbekova M, Turuspekov Y, Abugalieva S, Tuberosa R, Sanquineti M-C, Hollington PA, Aragues R, Royo A, Dodig D (2005) A high-density genetic map of hexaploid wheat (Triticum aestivum $\mathrm{L}$.) from the cross Chinese Spring $\times \mathrm{SQ} 1$ and its use to compare QTLs for grain yield across a range of environments. Theor Appl Genet 110:865-880

Ren ZH, Gao JP, Li LG, Cai XL, Huang W, Chao DY, Zhu MZ, Wang ZY, Luan S, Lin HX (2005) A rice quantitative trait locus for salt tolerance encodes a sodium transporter. Nat Genet 37:1141-1146 
Richards RA, Dennett CW (1980) Variation in salt concentration in a wheat field. Soil and water 44:8-9. Univ. Calif. Coop. Extension

Sahrawat KL, Ravikumar G, Murthy KVS (2002) Sulfuric acid selenium digestion for multi-element analysis in a single plant digest. Commun Soil Sci Plant Anal 33:3757-3765

Serraj R, Vasquez-Diaz H, Drevon JJ (1998) Effects of salt stress on nitrogen fixation, oxygen diffusion and ion distribution in soybean, Common bean and Alfalfa. J Plant Nutr 21:475-488

Shannon MC (1984) Breeding, selection and the genetics of salt tolerance. In: Staples RC, Toeniessen GH (eds)
Salinity tolerance in plants. John Wiley and Sons, New York, pp 231-254

Takehisa H, Shimodate T, Fukuta Y, Ueda T, Yano M, Yamaya T, Sato T (2004) Identification of quantitative trait loci for plant growth of rice in paddy field flooded with salt water. Field Crops Res 89:85-95

Weinberg RW, Lerner HR, Poljakoff-Mayber A (1984) Changes in growth and water- soluble solute concentrations in Sorghum bicolor stressed with sodium and potassium salts. Physiol Plant 62:472-480 